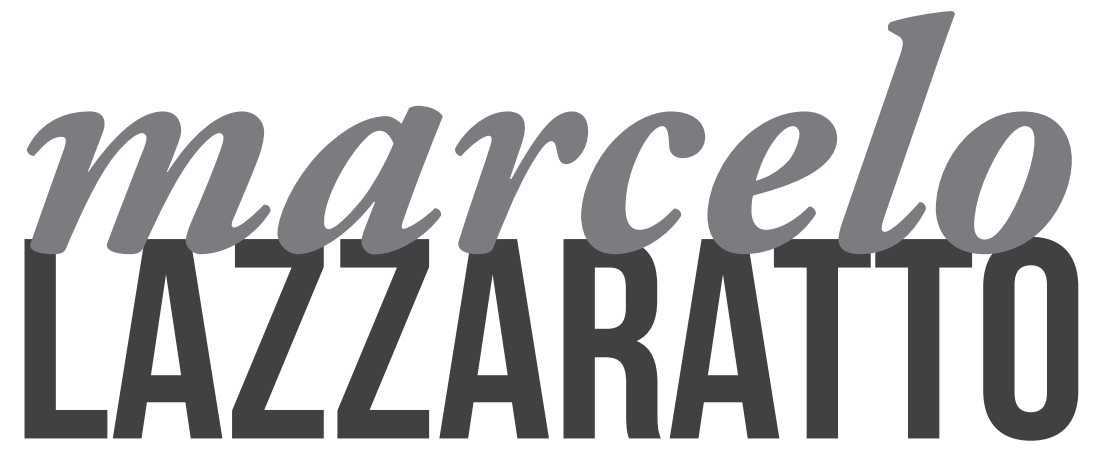

Universidade Estadual de Campinas (UNICAMP)

\title{
UM \\ ESPAÇO \\ PARA \\ RICARDO III
}

RESUMO> Este artigo correlaciona três tipos de palco -o elisabetano, a arena e o italiano-, no sentido de se discutir uma escolha de encenação vinculada à espacialidade, o que norteou todo o trabalho de criação da montagem de "Ricardo III", de William Shakespeare. O objetivo é o de, por meio dessa escolha, o espetáculo estabelecer um diálogo franco e direto com os espectadores dos tempos atuais.

PALAVRAS-CHAVEะ> Shakespeare; Ricardo III; Espaço; Cenografia 


\section{UM ESPAÇO}

\section{PARA}

\section{RICARDO III}

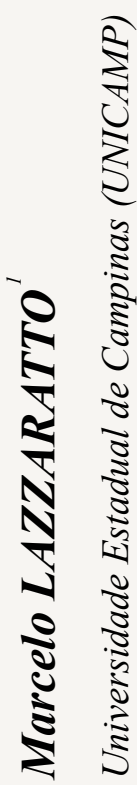

O certo é que terminamos de medir as consequências da passagem de uma "óptica da cena" (entendida metaforicamente como uma súmula de regras a ser respeitada para produzir um espetáculo "palatável”) para uma cena concebida como a interação de um olhar público e um olhar íntimo. (RYKNER, 2012, p.128)

No final de 2013, trouxe a público uma encenação de "Ricardo III", de William Shakespeare, no Teatro João Caetano, em São Paulo. Esse espetáculo faz parte do "Projeto Shakespeare 39", idealizado pelos produtores Alexandre Brazil e Erike Busoni, que tem como objetivo encenar todas as peças do autoringlês. Importante salientar que ações como essa são importantes e necessárias, haja vista que vitalizam a cultura e chacoalham os meios de produção e o pensamento estético. Um grande autor sempre gera desequilíbrio e movimento, é necessário, em qualquer lugar, em todo tempo, em qualquer cultura.

Em 2014, "Ricardo III" continuou sua trajetória por festivais e cidades do interior de São Paulo.

$\mathrm{O}$ que neste artigo pretendo discutir é a maneira como concebemos o espaço para que o reinado de Ricardo se materializasse na atualidade. Como o espaço cênico deveria ser tratado para que as metáforas shakespearianas de fato se materializassem em nossos dias? Quais elementos cenográficos contribuiriam para tanto? Qual seria o palco em que Ricardo III desfilaria suas máscaras em busca do poder?

Nos meados do século XVI, surge na Inglaterra um edifício teatral sui generis: o chamado Teatro Elisabetano, assim nomeado porque foi criado durante o reinado de Elizabeth I. Trazia características peculiares que muito ajudaram o gênio shakespeariano em sua construção poética. Na verdade, podemos mesmo dizer que esse tipo de palco foi o "espaço" que se abriu à poética
1 Professor Doutor do Departamento de Artes Cênicas da Unicamp. E-mail: marevi@uol.com.br. 
shakespeariana, contribuindo e muito para sua construção. Nesse palco, não havia cenografia, adornos ou telões que esclarecessem o lugar da ação. Tudo se dava por meio das palavras e das ações teatrais empregadas pelos atores na mise-en-scène.

Shakespeare, no final do século XVI e início do século XVII, escreveu seus textos para esse tipo de espaço, em que o ator e sua relação com o público se estabelece de maneira franca e direta, sem intermediações de qualquer aparato cênico. $\mathrm{O}$ jogo cênico tinha como elementos principais o espaço, a palavra e a faculdade do espectador em imaginar.

Bárbara Heliodora (2011) nos diz que, à época, as pessoas iam ao teatro mais do que para ver, para ouvir uma peça de Shakespeare. Essa minha montagem de "Ricardo III" levou isso em consideração. Optamos por dizer as palavras shakespearianas buscando encontrar toda sua força poética, dando contorno material às suas imagens. Queríamos que nossa montagem reencontrasse agora, em pleno século XXI, a vitalidade dessas potências para fazer o encontro entre o corpo e a imagem, entre a materialidade e a imaterialidade, a terra e o ar, o presente e o devir. Queríamos enfatizar a força da teatralidade da palavra, esta convenção pura e simples do teatro que desde a Grécia Antiga prendeu e cativou plateias, sem a necessidade de recursos externos. A palavra geradora de imagens e sensações. A palavra criadora de espaços e personagens. Palavras que divertem, entretêm e redimensionam nossa maneira de enxergar as coisas do mundo. Em Shakespeare, as palavras, os versos e seus ritmos devem, além de expor seus belíssimos significados, encantar o espectador também por sua sonoridade quando vocalizados pelo ator. Shakespeare foi um grande "construtor" de palavras. $\mathrm{Na}$ verdade, ele inventou milhares de palavras em suas obras e o jogo de aliterações, de assonâncias, de antíteses, de metáforas e da sinestesia tramado por ele deve ser sempre reprocessado para melhor se adequar à época e ao lugar em que a peça for encenada. Adequar-se às transformações da língua, enfim.

Para tanto, torna-se imperioso preocupar-se tanto com a emissão, quanto com a recepção dessas palavras. A encenação, a meu ver, deve priorizar esse aspecto e coordenar muito bem aquilo 
que se vê com aquilo que se ouve, evitando eventuais dicotomias entre forma e conteúdo. Pensando nessa questão e aproximandome do objeto específico deste artigo -o espaço cênico-, quis conceber um lugar em que a visualidade da peça, ancorada em alguma espacialidade construída como cenografia, não impedisse, ou, mesmo, tornasse-se um ruído à capacidade humana de visualizar a partir da sugestão.

O público muito interessa ao teatro shakespeariano: seduzilo, cativá-lo, estimulá-lo, entretê-lo eram, sem dúvida, objetivos centrais dos autores daquele período. Shakespeare fez um teatro popular. Eram duas, três peças por mês. Ele vivia no teatro. Seu trabalho era contínuo, constante. Escrevia, fazia, arrumava. O que funcionava ficava, o que não funcionava, não se repetia. Assim ele foi construindo sua poética.

No palco elisabetano, os atores veem-se cercados pelos espectadores, devido ao proscênio avançado. Essa simples característica, essa proximidade, muito ajudou para que os aspectos narrativos de sua dramaturgia desenvolvessem-se. Um exemplo desse desenvolvimento é o aparecimento da comicidade logo após uma cena lírica. Aspecto esse que se fundamenta também a partir de uma necessidade de se entreter o público. Porque se Shakespeare vivia no teatro, ele também vivia do teatro. Era seu ofício, seu ganha pão. Ele precisava entreter os espectadores por três horas no mínimo. Para isso, suas peças precisavam conter muitos ingredientes, movimentos e dinâmicas variáveis. Em suas peças, aspectos épicos, líricos e dramáticos encadeiam-se com naturalidade, bem como a comicidade e a dramaticidade.

E, para isso, sobre um espaço essencialmente vazio, seu teatro utilizava as convenções. Do interior do castelo ao campo de batalha, nenhuma transição: corte e convenção. Faz-se necessário salientar que a convenção é um dos elementos que permitem com que o teatro continue sendo uma arte essencialmente popular. Ela aproxima o espectador porque o provoca a participar da construção poética no momento presente de sua fruição. A convenção surpreende-o, emociona-o, torna-o mais "inteligente" e essas sensações são absolutamente prazerosas e recompensadoras. É 
gostoso ser ativado dessa maneira. Paradoxalmente, a artificialidade da convenção promove a organicidade do envolvimento. E muito da riqueza do jogo de convenções do teatro shakespeariano nasce do espaço...

O Teatro Elisabetano, mesmo tendo capacidade para duas, três mil pessoas, tem uma arquitetura que proporciona envolvimento e proximidade. Todos os vetores convergem para o proscênio. Mesmo no segundo andar do balcão lateral, o espectador, ali sentado, sente-se próximo ao ator. Os atores percebem-se envolvidos pelos espectadores e os espectadores enxergam-nos e ouvem-nos muito bem. É um estrutura arquitetônica que visa à clareza. Tudo é claro no palco de Shakespeare, assim como seus textos. Tudo o que ele pretende afirma-se com clareza e nitidez. Os contrastes entre os gêneros que ele habilmente manipula (como já dito, sua dramaturgia é impura, híbrida), as variações emocionais, a justaposição de tramas paralelas espelhando personagens da nobreza com personagens populares... tudo o que ele pretende, acontece com clareza sobre um tablado que nada mais tenciona do que se revelar com nitidez. O palco elisabetano quer se mostrar, não quer deixar nada subentendido, não quer escamotear, nem se afirmar através de meias palavras ou meios gestos. Ele é franco. E exige franqueza. Costumo dizer ao atores quando estamos ensaiando uma peça de Shakespeare, e assim foi em "Ricardo III", que, assim como ele, nossa interpretação tem que ser franca. Shakespeare é franco. Seu tablado é franco. Direto, claro, objetivo, nítido.

Aproximando-nos de "Ricardo III"... Uma inquietação revelou-se, creio que comum a todo diretor que começa a trabalhar em uma montagem com um texto clássico. Qual a maneira de traduzilo à contemporaneidade sem perder sua espessura e abrangência? Haverá cortes no texto? Quais os critérios? O espectador de hoje suporta assistir a algo de mais de três horas de duração?

"Ricardo III" é uma das peças mais longas de Shakespeare... Tem mais de 50 personagens... As pessoas não a entendem३̧ geralmente. Há várias personagens rivais com o mesmo nome... Quem não conhece bem a história da Inglaterra perde-se na trama ou fica a ver navios... Comentários comuns, quase clichês, sobre 
montagens dessa peça.

Peter Brook já nos dizia a respeito do trato com peças clássicas: "não é apenas uma questão de cortejar uma plateia. É uma tarefa ainda mais difícil, a de criar obras que provoquem no público uma fome e sede fortíssimas" (BROOK,1970,p.77). É sempre bom ter isso em vista. O trato sobre a obra deve sempre levar em consideração o público que irá assistir. Devemos instigá-lo, provocá-lo, tirá-lo de sua suposta passividade.

"Ricardo III" é uma peça essencialmente política. Para, ao mesmo tempo, dar conta e enfatizar esse traço determinante do texto e manter as premissas até aqui explanadas em relação à nitidez e à clareza com que seus textos mostravam-se no palco elisabetano, resolvi, em um primeiro momento, pensar na possibilidade de realizar a montagem em um teatro tipo arena.

A arena é um espaço político por excelência. Sua origem remonta-se ao que gerou a Ágora na Grécia Antiga. Sabe-se que, antes da formação da Pólis, havia, na Grécia, uma classe de guerreiros separada dos agricultores e dos pastores. Quando se reuniam em formação militar para debater assuntos diversos, formavam um círculo. Segundo o antropólogo helenista francês Jean Pierre Vernant,

No círculo assim formado constitui-se um espaço em que se dá um debate político, com o que os gregos denominam o direito à livre palavra. No início do canto II da Odisséia, Telêmaco convoca desse modo a ágora, isto é, ele reúne a aristocracia militar de Ítaca. Estabelecido o círculo, Telêmaco avança para o interior e se coloca no centro; segura o cetro na mão e fala livremente. Quando ele termina sai do círculo, um outro toma seu lugar e lhe responde. Essa assembleia de "iguais", que constitui a reuniáo dos guerreiros desenha um espaço circular e centrado em que cada um pode dizer livremente o que lhe convém. Esse ajuntamento militar tornar-se-á, depois de uma série de transformaçóes econômicas e sociais a Ágora da cidade em que todos os cidadáos (de início uma minoria de aristocratas, depois o conjunto do dêmos) poderão debater e decidir em comum os negócios que lhes concernem coletivamente. Trata-se, pois, de um espaço feito para a discussão, de um espaço público opondo-se às casas privadas, de um espaço político em que se discute e em que se argumenta livremente (VERNANT, 1990, p.253). 
Naquela altura, pensei que esse traço característico da forma circular, que, futuramente. seria determinado como Arena, serviria como base de toda ação cênica e reforçaria o debate e a luta pelo poder contido na obra. O público seria copartícipe das ações de Ricardo em sua busca obsessiva pela coroa.

Mas em São Paulo existem poucos teatros de arena que comportem uma montagem com uma equipe de 20 pessoas... O teatro que existe, naquele momento, estava ocupado por um espetáculo de sucesso que ficaria ali em cartaz ainda por um bom tempo. Esse obstáculo quase que intransponível da produção levoume a seguir um caminho que se mostrou, a meu ver, mais contundente à concepção do espetáculo e aos objetivos que pretendia ao trazer a público esse texto de Shakespeare nos dias de hoje.

Sempre que um dos chamados Dramas Históricos de Shakespeare, que se esmera em contar a história da Inglaterra, é encenada em algum lugar que não no Reino Unido, surge a pergunta: para quê? O que interessa, por exemplo, aos brasileiros, uma história que está ancorada em alicerces tão díspares aos nossos, como a estrutura feudal, a Monarquia, o Parlamento?

"Ricardo III" veio a público em terra brasilis para mostrar o jogo político e as tramas engendradas nos bastidores, servindo de espelho ao que aqui acontece nos corredores do Congresso, nas imbricadas linhas da telefonia celular, nas redes dos conglomerados financeiros, etc.

Tudo aquilo que se planeja às escondidas, pelas costas, nos meandros, nos cantos e nos clubes, movido pela ambição e pela cobiça, nossa montagem fez a opção de revelar, deixar às claras, tornar público.

Colocaram-se francamente, e perante todos, do mesmo modo, as dores e as angústias de personagens que perderam parentes, pais, filhos e irmãos nessa luta desenfreada pelo poder. Nada era escamoteado. Nada escondido. Nada dissimulado.

A partir dessa objetivação, foi concebida nossa encenação. E a escolha do espaço cenográfico foi determinante para alcançarmos esses objetivos.

Iríamos certamente realizar o espetáculo em um teatro 
convencional com um palco à italiana. Mas não queria abrir mão do círculo, da arena, da Ágora... tinha a convicção de que o uso da circularidade seria bem-vindo à construção do espetáculo. Então, surgiu-me uma imagem que definiria a encenação e que determinaria todos os encaminhamentos que um diretor tem de realizar quando conversa com os artistas cocriadores de uma montagem: atores, cenógrafo, figurinista, iluminador, sonoplasta...

Pensando na qualidade da fruição de um espetáculo que poderia ter três horas de duração, não queria deslocar o público radicalmente de uma certa zona de conforto. Não queria fazer com que assistisse ao espetáculo muito tempo em pé, por exemplo, ou promover deslocamentos de um lugar a outro, o que poderia gerar certo ruído e atrapalhar o entendimento de uma peça que, como já disse, é complicada e que necessita que a palavra, além de muito bem dita, possa ser ouvida com clareza, sem ruídos de toda e qualquer espécie.

Mantê-lo sentado na poltrona de um teatro convencional não seria má ideia. Sua atenção estaria direcionada. Sabemos que uma das maiores virtudes do palco italiano é o uso da perspectiva que canaliza o olhar ao ponto de fuga. Todos os olhares, toda a atenção, todas as linhas convergem a esse ponto, o que favorece a clareza da imagem composta em cena. Para favorecer ainda mais essa qualidade, o palco italiano possui uma moldura na boca de cena tornando o palco uma imensa tela tridimensional. Ao fazer essa opção corria, sim, o risco de que essa posição confortável levasse o espectador ao sono ao se deparar com uma saraivada de palavras ditas por inúmeros personagens compondo construções frasais nada cotidianas. Porém, esse corpo sentado confortavelmente em sua poltrona seria sacudido invariavelmente...

Se a estrutura do palco italiano é historicamente criticada por favorecer, por meio do ilusionismo que sua caixa cênica é capaz de criar, certa inércia do espectador visando à manutenção do status quo, uma vez que essa estrutura arquitetônica fortalece-se no período em que a burguesia assume o poder e quer ver no teatro a si mesma, em "Ricardo III", fiz uso desse "lugar comum" e instaurei uma linha que desequilibrou o senso organizacional da percepção do 
espectador: um círculo rompe a moldura e as linhas retas do palco italiano, apoia-se em seu proscênio e invade o espaço do público.

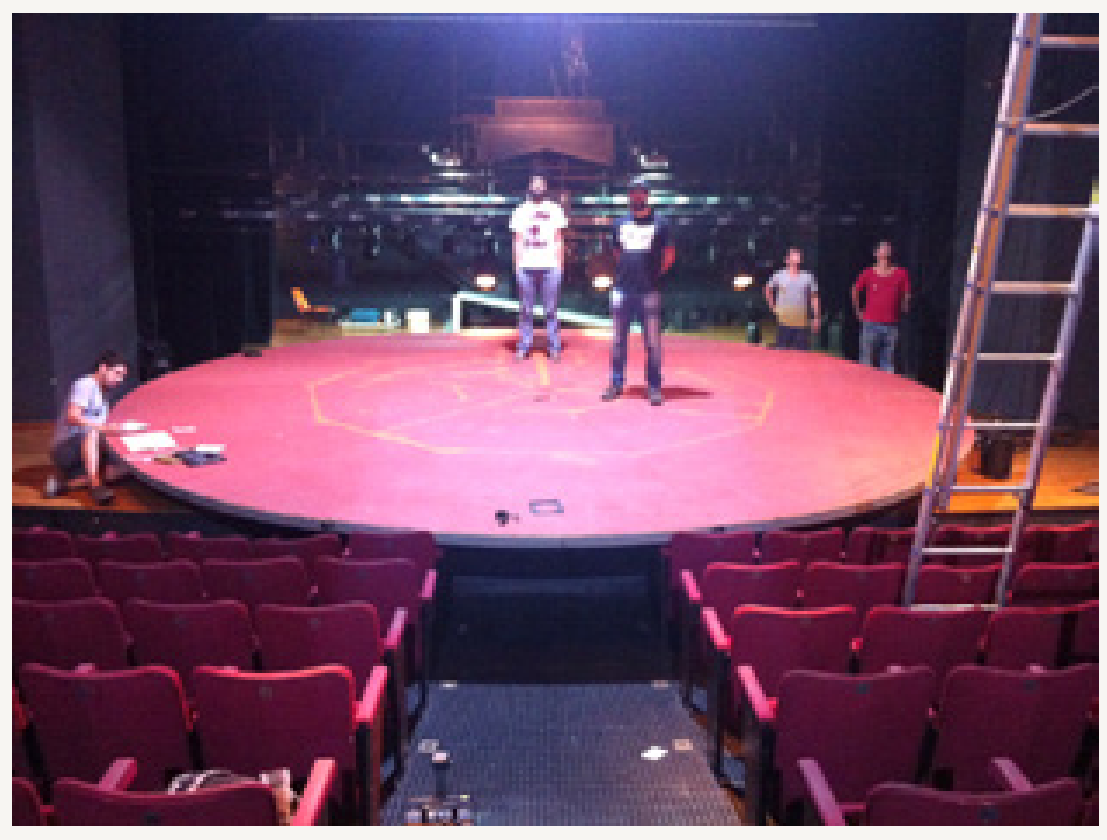

Montagem do cenário no Teatro João Caetano em São Paulo

Esse foi o "gesto" dessa encenação. Um único gesto que determinou todas as linhas das marcações cênicas, bem como o super-objetivo do espetáculo.

Trata-se, sim, de um gesto político. A Ágora invadindo o espaço burguês. A circularidade desnorteando o retilíneo. $O$ debate político exposto e impulsionando o espectador a participar. Com isso, a plateia se sentiria pertencente àquele imaginário. Todos seriam cidadãos daquele reinado e poderiam refletir objetivamente sobre os mandos e os desmandos dos governantes, sobre os conchavos e os assassinatos que Ricardo realizaria em sua obsessão pelo poder.

Essa encenação de "Ricardo III" acontece sobre uma arena rompendo a quarta parede do palco italiano. A arena, espaço político por excelência, debruça-se sobre a plateia comodamente assentada nas poltronas do teatro. O espaço inteiro do edifício teatral -palco e plateia- iluminados e interligados. Essa linha de tensão sobre os espectadores reforçou o objetivo da montagem que pretende expor, sem dúvidas e meios tons, o descaramento do jogo político contemporâneo. 


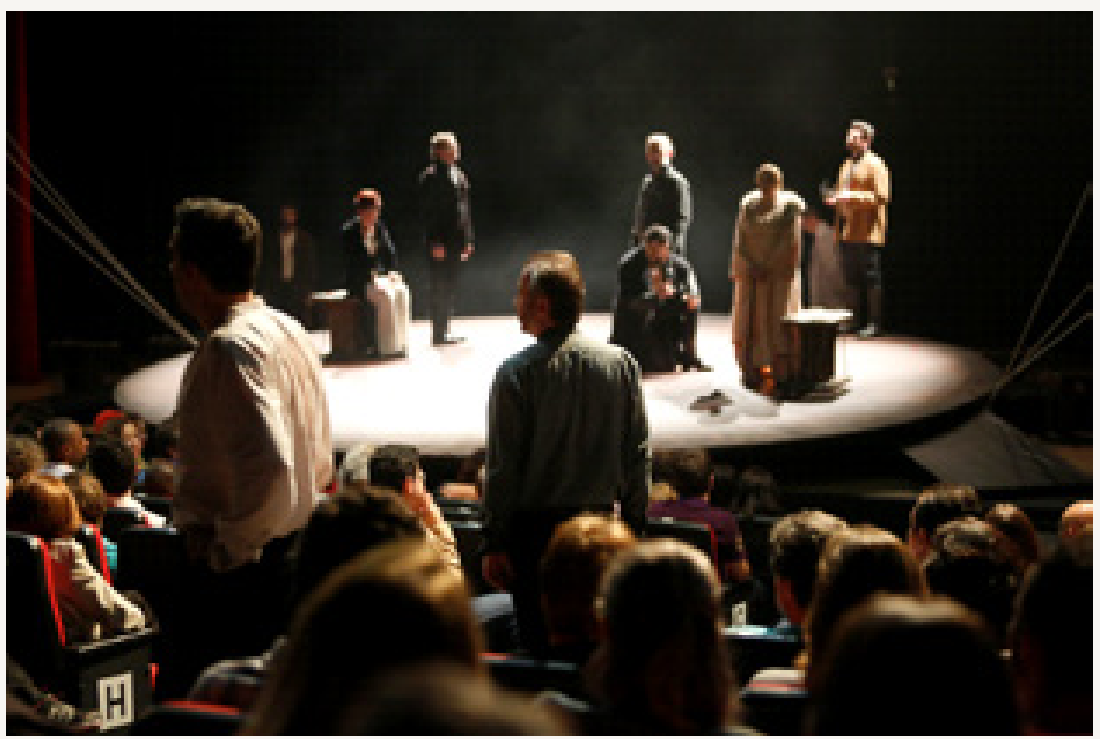

Cena dos Cidadãos - Ato II, cena 3

Nesta fotografia, é possível perceber com clareza o tablado circular debruçando-se, invadindo o espaço da plateia, interligando o lugar que seria da representação com o lugar da recepção. Os atores agiam também nos dois espaços, para que o público pudesse se sentir participando das questões suscitadas na peça como se fossem cidadãos daquele reinado.

Para reforçar ainda mais esse "gesto", resolvi inclinar $70 \mathrm{~cm}$ a parte de trás do tablado circular, aumentando, assim, a proximidade com a plateia, e também para os atores ficarem mais elevados, não havendo, enfim, nenhuma interferência visual - de qualquer lugar que se sentasse, o espectador teria dos atores uma visão limpa, desimpedida.

Outra aspecto que reforçou a interação palco/plateia foi a construção de rampas que saíam da arena e conectavam-se diretamente aos corredores da plateia. Assim, o trânsito entre os ambientes acontecia de maneira fluida e dinâmica. Os atores invadiam a cena ou posicionavam-se ao lado do público, sem esforço. Essa estrutura espacial foi determinante para que os pressupostos da encenação encontrassem êxito.

Depois dessa decisão, cenas que, em um primeiro corte, 
tinham sido eliminadas voltaram. Mais especificamente, a cena dos Cidadãos (ato II, cena 3), em que a população revela a inquietação social gerada pelos acontecimentos e pressente, ao detectar mudanças atmosféricas, que as coisas não estão bem; e a cena do Escrivão (ato III, cena 6), que, em recorte épico, conta à plateia que recebeu uma ordem para atestar um óbito antes mesmo de ele ocorrer. Essas cenas eram essenciais à encenação que tinha como super-objetivo incitar o espectador de hoje a fazer parte do debate político que o texto de Shakespeare propõe e correlacioná-lo com a sua realidade político-social.

CIDADÃO 3. Quando as nuvens são avistadas, os homens prevenidos vestem suas casacas;

Quando caem as folhas grandes, entâo o inverno está à mão;

Quando o sol se póe, quem não procura pela noite?

Tempestades fora de tempo fazem os homens esperar a escassez.

Tudo poderá ficar bem; mas, se Deus assim fizer,

É mais do que merecemos ou do que eu espero.

CIDADÃO 2. Verdade, os corações dos homens andam cheios de medo.

Não se consegue argumentar com ninguém

Que não pareça pesado e aterrorizado.

CIDADÃO 3. Antes de dias de mudança, é sempre assim;

Por instinto divino, a mente desconfia

Dos perigos seguintes; como é prova

A água crescer antes da tempestade.

Mas seja o que Deus quiser.

Por meio dessas escolhas, essa montagem pôde alcançar seus objetivos. É claro que muitos outros fatores contribuíram 
para isso: o trabalho dos atores, a iluminação, a trilha sonora, o trabalho dos cenotécnicos... O teatro é uma arte que contém muitas outras, mas, de certo modo, todas operaram a partir e em relação a esse conceito espacial. Ali, esse nosso Ricardo III agia às claras. A arena pública era o seu tablado. Ali, ele se fazia ator de muitas caras, muitos estilos. Caracterizava-se e neutralizava a expressão por conveniência. Camuflava-se, revelando-se. Embora trouxesse em si, inequivocamente, a marca da maldade, como um camaleão, transformava-a em atração.

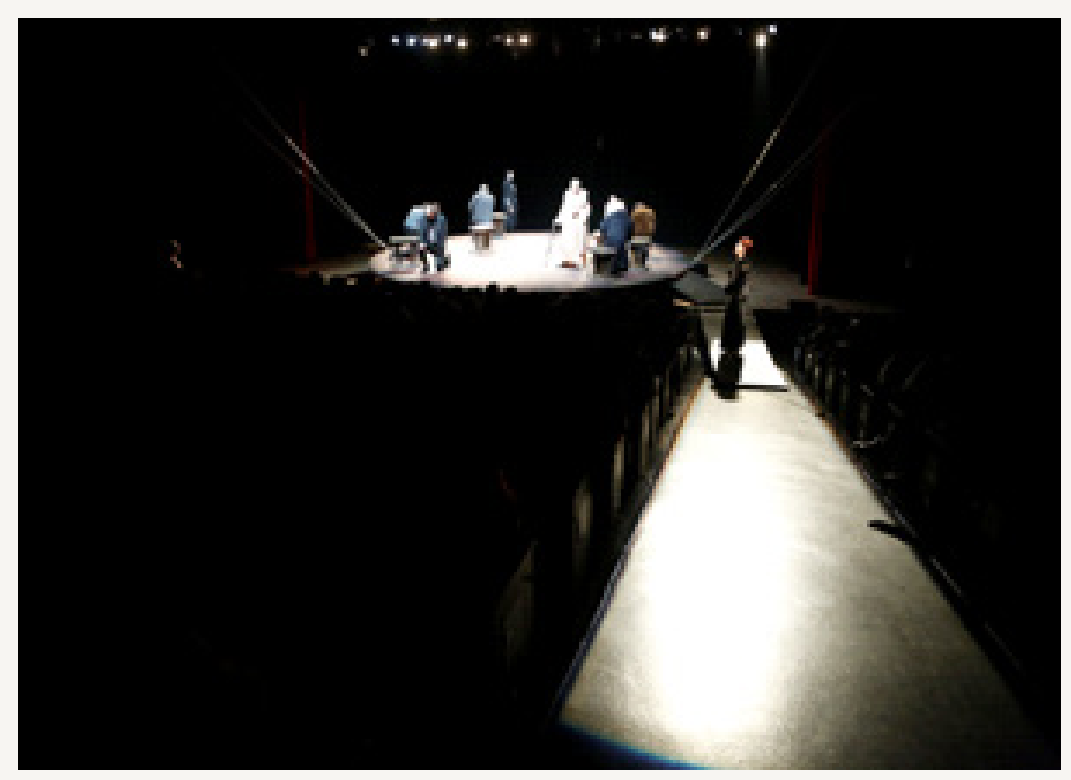

A Arena e suas Rampas

\section{REFERÊNCIAS BIBLIOGRÁFICAS:}

BROOK, Peter. O teatro e seu Espaço. São Paulo, Vozes, 1970.

HELIODORA, Barbara. Encontros: Shakespeare e a Tradução. In: Sobe? Ano I, n.1. São Paulo, 2011.

SARRAZAC, Jean-Pierre. Léxico do drama moderno e contemporâneo. São Paulo, Cosac Naify, 2012. 
SHAKESPEARE, William. Ricardo III. Tradução de Jorge Louraço.

VERNANT, Jean Pierre. Mito e Pensamento entre os Gregos: estudos de psicologia histórica. Rio de Janeiro, Paz e Terra, 1990.

\section{ABSTRACT}

This paper correlates three types of stages - the Elizabethan, the arena and the Italian - in order to discuss a choice of spatiality related to the scenario that guided all the work of creating the production of "Richard III" by William Shakespeare, and through it, the scene could establish a true and direct dialogue with the viewers from the actual times.

\section{KEYWORDS}

Shakespeare; Richard III; space; scenery 